\title{
Laboreal
}

Volume 12 №2 | 2016

Equipamentos de Proteção Individual II

\section{Para una psicología histórica}

Para uma psicologia histórica

Pour une psychologie historique

For a historical psychology

\section{Ignace Meyerson}

Traductor. Cecilia De la Garza y Mario Poy

\section{(2) OpenEdition}

\section{Journals}

Edición electrónica

URL: http://journals.openedition.org/laboreal/2733

DOI: 10.4000/laboreal.2733

ISSN: 1646-5237

Editor

Universidade do Porto

\section{Referencia electrónica}

Ignace Meyerson, «Para una psicología histórica », Laboreal [En línea], Volume 12 N² | 2016,

Publicado el 01 diciembre 2016, consultado el 24 septiembre 2020. URL : http://

journals.openedition.org/laboreal/2733; DOI : https://doi.org/10.4000/laboreal.2733

Este documento fue generado automáticamente el 24 septiembre 2020.

\section{c) (i) (8)}

Laboreal está licenciado com uma Licença Creative Commons - Atribuição-NãoComercial 4.0 Internacional. 


\title{
Para una psicología histórica
}

\author{
Para uma psicologia histórica \\ Pour une psychologie historique \\ For a historical psychology \\ Ignace Meyerson \\ Tradución : Cecilia De la Garza y Mario Poy
}

\section{REFERENCIA}

Artigo original: Meyerson, I. (1948). Prólogo. Dans Le Travail et les Techniques [pp. 7-16]. París: PUF. Retomado de I. Meyerson (1987). Ecrits. Pour une psychologie historique [pp. 221-227]. Paris: PUF.

1 Los textos de esta recopilación son los de la ponencias presentadas durante la Jornada de Psicología et historia del trabajo y de la técnicas organizada el 23 de junio de 1941, por la Sociedad de Estudios psicológicos de Toulouse.

2 Esta fue fundada en mayo del 1941 [1] dándosele un objetivo comparativo: intentar de comprender lo mejor posible la plenitud de las conductas, especialmente en cuanto a actos, tareas y obras complejas del ser humano, y por ende comprender al ser humano en su totalidad. Si en un animal un comportamiento parcial solo se lo entiende bien analizándolo desde la vida y el entorno biológico, una conducta humana, una obra humana, que se juega en el interior de un margen biológico sumamente amplio, no se la entiende más que por su significación y por su lugar en el conjunto de las conductas. Se la debe analizar siempre en relación con las series a las cuales ésta pertenece, y los grupos humanos de los cuales ella traduce las necesidades, las costumbres y las innovaciones, las normas.

3 La primera reunión de la nueva sociedad se llevó a cabo el 15 de mayo de 1941. Se trataba de una sesión de estudio de método general, pero que debía servir de prefacio y de preparación de la sesión sobre el Trabajo. He aquí como, en el llamado dirigido a los futuros miembros, resumía ya nuestro programa: “El esfuerzo científico en Psicología le 
da un lugar muy importante actualmente a los estudios comparativos. El estudio de las conductas de los sentimientos, del pensamiento, se apoya cada vez más sobre sobre materia concreta. La Psicología se empeña en analizar los productos de la actividad, del pensamiento humano, la historia del esfuerzo espiritual y material; de manera más general, la historia natural y social del ser humano, también la de los animales, vistas a través del mayor número posible de manifestaciones. Esas investigaciones, cuyos resultados fueron importantes, implican la convergencia de técnicas diversas: el psicólogo debe recurrir a la ayuda de antropólogos, etnólogos, geógrafos; liguistas y filólogos; historiadores, historiadores de letras, de artes, de religiones; juristas; así como a la ayuda, ya adquirida anteriormente, de filósofos, biólogos, físicos".

La agenda de la reunión fue la siguiente:

I. Meyerson: Qué ayuda, la investigación objetiva en piscología, le demanda a las disciplinas vecinas.

II. MM. H. Vallois, D. Faucher, V. Magnien, A. Aymard, R. Naves, J. Maury, Mgr B. de Solages: Lo que ofrecen la antropología, la geografía, la filología y la lingüística, la historia, los estudios literarios, la ciencias jurídicas, los estudios religiosos, lo que le piden a la Psicología.

5 Resumamos en unas cuantas líneas las partes expuestas en esta sesión que son las más directamente útiles a las investigaciones sobre el Trabajo: el análisis de los aportes hechos a la Psicología por las disciplinas vecinas.

6 El objeto de la antropología, decía M. Vallois, es a la vez la morfología del ser humano, el estudio del lugar de éste en la naturaleza, del origen de le forma Homo y de su espíritu y, por otra parte, aquella de las relaciones de los grupos humanos entre ellos.

7 La geografía, por su estudio de las relaciones del ser humano con su medio físico, aporta a la Psicología comparativa una contribución evidente, señalaba M. Faucher. Los fenómenos de temperatura, de pluviometría, etc., son un factor que determina el género de vida y por ende de la mentalidad. El estudio del relieve comporta el de la doble vida: así en los Pirineos, los pueblos de los valles con la propiedad individual, las estibas entre 1600 y $2600 \mathrm{~m}$ propiedad colectiva. La mentalidad de la montaña pirinea está ligada a un doble régimen de derecho y a los usos dependientes de este. La conservación de algunas costumbres y de un idioma original de un país abierto sin embargo a la penetración, como el País vasco, plantea el problema de las condiciones para mantener las especificidades locales, etc.

8 La filología y la lingüística, indicaba M. Magnien, necesitan a menudo el análisis psicológico. Los hechos psicológicos actúan sobre las leyes de la fonética general y de la fonética específica de cada lengua. Las condiciones psicológicas (además de las condiciones sociales, de las condiciones de lugar y de tiempo) determinan la disociación de los grupos lingüísticos o la formación de lenguas nuevas. Un estado de ánimo colectivo forma, dirige, mantiene, embellece cada lengua particular. En una lengua dada, tal lengua particular, como la lengua poética, está ligada a condiciones que se deben estudiar en Psicología. El uso de tal vocabulario, la expresión clara o velada, la expresión directa o la expresión evocadora traducen también hechos psicológicos complejos que se tienen que analizar.

9 La historia, señalaba M. Aymard, ha aportado a la Psicología innumerables ejemplos humanos individuales o colectivos. Aporta un método crítico permitiendo utilizar testimonios. Plantea y permite aclarar dos problemas con los cuales se enfrenta necesariamente la Psicología: él de las relaciones entre el individuo y la colectividad, 
bajos sus diversos aspectos; y el de las causas, accidentales o permanentes, particulares o generales.

Los estudios literarios, exponía Raymond Naves, incumben varios campos: la historia, cuando esclarecen los lazos del autor y de la obra; a la exégesis, cuando intentan explicar el hecho literario; a la estética y a la crítica; a la filología, cuando el verbo en si es su objeto; a la poética, cuando se trata de remontar a los origines mismos del "hacer" literatura. En todas esas direcciones rencuentran la Psicología.

11 Para M. Maury, el análisis de las reglas de Derecho y la investigación de su razón de ser, mediante el derecho comparativo y la historia del derecho, permiten descubrir bajo las instituciones, las tendencias psicológicas, precisar "círculos de cultura", tipos de civilización. Algunos conceptos utilizados por las ciencias jurídicas, como el de la persona, el del sujeto del derecho, corresponden a conceptos psicológicos. Los problemas de sociología jurídica y de filosofía del derecho incumben a la Psicología. Las leyes formuladas por las Ciencias económicas, en la medida en que su existencia se demuestra, son significativas de tendencias principales del ser humano.

El Hecho religioso, para monseñor de Solages, es ante todo un hecho psicológico y, de manera secundaria, un hecho sociológico. Se extiende a todos los campos de la vida psíquica. Tiene que ver con la inteligencia por la parte doctrinal de las religiones, con la afectividad por el sentimiento religioso, con la voluntad porque toda religión exige de sus creyentes y también por los motivos de acción que les ofrece.

Esperamos poder publicar algún día estas ponencias. Muestran aspectos de un estudio objetivo de las funciones superiores del ser humano dirigido por investigaciones convergentes y comparativas. Faltará una contribución a esta compilación: la de Raymond Naves, profesor de literatura francesa de la Facultad de Letras de Toulouse, uno de los jefes de la resistencia, muerto durante su deportación.

14 La segunda reunión de la sociedad fue la Journée de Psychologie et d'Histoire du Travail et des Techniques (Jornada de Psicología y de historia del trabajo y de las técnicas). La convocación decía:

15 "Deseando esclarecer a la vez el valor psicológico de los estudios de historia comparativa del esfuerzo humano, espiritual y material, y los resultados de investigaciones acordadas, aplicadas a un problema, la Société d'Etudes psychologiques de Tolouse decidió hacer de su primera sesión de trabajo una reunión excepcional, una "Jornada", dedicada por completo al examen de un solo problema y un problema concreto. Se organizó el lunes 23 de junio del 1941 en la Facultad de Letras, anfiteatro Marsan, una Jornada de Psicología y de historia del trabajo y de las técnicas."

El estudio del trabajo [2] fue realizado al principio de manera un poco fragmentada y dispersa. Fueron los psicólogos los primeros que abordaron los problemas de esfuerzo muscular y de la fatiga, y después los del funcionamiento del motor humano, mucho más complejos. Notaron los diversos aspectos de la participación de todo organismo del trabajo de un grupo de músculos. El estudio de la fatiga y de sus diversas formas mostró aún más esas acciones conjuntas, así como las repercusiones prolongadas, y a menudo a largo plazo, de estados que a primera vista podían parecer limitados. El estudio de las curvas del trabajo y de la fatiga reveló además variaciones individuales y, en el mismo individuo, diferencias de reacción según la naturaleza y las condiciones de trabajo. La fisiología llevaba así a la Psicología. 
17 Cuestiones prácticas de rendimiento del trabajo suscitaron otra serie de estudios y de aplicaciones que todo mundo conoce muy bien: aquellos que se agrupan bajo un nombre un poco presuntuoso de organización científica del trabajo y de racionalización. Allí también, se creyó al principio poder limitarse a hechos localizados y parcelarios. Mediante el estudio del tiempo de diversos movimientos parciales del trabajo, el cronometraje, la eliminación de los tiempos muertos, se pensaba aportar soluciones validas desde un triple punto de vista científico, económico y social a los problemas del trabajo. Pero no fue así. Los representantes más expertos de los grupos obreros, y al mismo tiempo que ellos, los fisiólogos y los psicólogos pudieron mostrar que el sistema Taylor y sus derivados habían analizado y comprendido mal el trabajo. El ser humano en el trabajo no es una suma de movimientos y de tiempos parciales, y el ser humano no solo es ser humano en el trabajo. Lo que se le escapa al cronometro, en parte o por completo, no es menos importante que lo que se mide. Como la fisiología, la organización del trabajo estaba poco orientada hacia el ser humano en su conjunto.

La psicotécnica, ciertamente disciplina aplicada, pero disciplina psicológica, lo entendió mejor desde el principio. El objeto de esas investigaciones era en un principio, el mismo que el del "scientific management", pero su personal tenía tanto una formación, como una perspectiva distinta. Las organizadores eran técnicos, ingenieros. En el motor humano consideraban sobre todo el motor y olvidaban al hombre. Los psicotécnicos pensaban mucho más en el factor humano, aun cuando buscaban obtener el mejor rendimiento y formulas económicamente satisfactorias. Los tests de aptitud que desarrollaron fueron ciertamente tests de detalle, pero también buscaron pruebas que permitieras identificar la participación de las distintas grandes funciones en el trabajo parcelar y las repercusiones del trabajo, y de la fatiga en esas funciones.

19 La selección y la orientación profesionales que, se supone, debían únicamente aplicar y sistematizar los datos de la psicotécnica, y que intervenían aparentemente en el mismo campo que ella, dieron a los problemas del trabajo un nuevo matiz. La adaptación del hombre al oficio y del oficio al hombre, las relaciones entre el hombre y la herramienta, del hombre y la máquina, del hombre y del trabajo en general, la distribución de los hombres en los oficios fueron examinados esta vez ya no más de manera fragmentaria y abstracta, sino en grupos humanos reales, complejos, que comprendían numerosos individuos, viviendo en condiciones sociales, económicas, técnicas restrictivas. Lo social, lo político, lo psicológico: la vida en todas sus formas se manifestaba detrás de esos problemas de determinación profesional. El estudio de las aptitudes mostró a los orientadores que era necesario considerar la adaptación y la adaptabilidad, más que lo orgánico, lo preformado. La disposición es sin duda orgánica originalmente, pero sobrepasa rápidamente ese nivel orgánico, y se vuelve adaptación progresiva, técnica y social. Además no es solo una habilidad localizada, sino lo más a menudo el "hacer" de todo ser humano, de toda la persona.

20 Quien dice psicotécnica y orientación profesional dice técnica en general y organización social del trabajo. Una y otra tienen que ser consideradas en su contexto concreto, en su historia. Al hombre en el trabajo se lo entiende mejor por la historia del trabajo y de las técnicas: historia material y al mismo tiempo historia social, moral y psicológica.

21 La historia material del trabajo es la que parte de sus primeras formas artesanales y rurales hasta el maquinismo contemporáneo. A esta no se le puede separar de la historia psicológica y social, ya que es la historia de las sucesivas invenciones técnicas y 
de sus repercusiones en el ser humano: sobre las condiciones de su existencia y su vida mental. También es la historia de las formas del trabajo adaptadas a los diversos instrumentos inventados sucesivamente. A cada momento hay que considerar la herramienta y al hombre delante de la herramienta. El instrumento, la máquina plantean múltiples problemas al psicólogo; se dan algunos ejemplos: las formas del pensamiento comprometido en la invención; las relaciones y la influencias reciprocas de la investigación pura y de la ciencia aplicada en la invención; las razones de la aceptación, o de la no aceptación de una innovación, etc. La nueva técnica actúa en el hombre, lo forma. El hombre delante de la herramienta puede ser amo o engranaje; se puede sentir más o menos dependiente, puede participar más o menos y de formas diversas con la máquina.

A la historia de las primeras formas de la técnica se la conoce poco. No se sabe prácticamente nada de las primeras grandes invenciones. No se conocen ni las condiciones de los descubrimientos, ni los procedimientos implementados, ni las repercusiones de las innovaciones sobre el espíritu del hombre; y tampoco se sabe bien qué lugar tenía esa actividad de transformación de la materia, en las preocupaciones y en la escala de valores de los hombres. Cosa singular: de las poblaciones arcaicas, conocemos los hechos de la vida social y económica, que durante largos periodos cambiaron poco y que acabaron por pasar a un segundo plano sin dejar rastro en el progreso posterior. Y lo que estuvo al origen de ese progreso empieza apenas a ser estudiado.

El trabajo de los hombres se desempeñó en el seno de las sociedades organizadas de manera diferente por los hombres agrupados de manera diversa. La división del trabajo siempre ha estado subordinada a una estructura social y económica, y a la división del trabajo se le asocia la distribución de los hombres en los oficios. Las formas de comunidad del trabajo han variado y con ellas la atmosfera social, fuente de preocupación o de entusiasmo, y también fuente de juicios: sobre el trabajo, sobre su perfección material, sobre su valor religioso y moral. La historia de la idea del trabajo, a menudo tratada aparte, aparece así en la prolongación de la historia social del trabajo. Las diversas concepciones del trabajo elaboradas por las religiones y las morales están ligadas a la estructura de las sociedades que tenían esos pensamientos religiosos y morales. Se sabe en algunos casos, se presiente en todos, pero quisiera uno poder esclarecer esa relación. Dichas concepciones están ligadas también a la civilización técnica de esas sociedades y al régimen de su progresión. Esto también plantea problemas al psicólogo. ¿Acaso hay una relación entre el progreso técnico y la valorización del trabajo? Eso se ha dicho en algunas ocasiones. Si esto es cierto, $-\mathrm{y}$ se debería poder elucidar- ¿Cómo el pensamiento técnico ha actuado en el pensamiento moral?

Hay una historia, una carrera psicológica de la idea del trabajo.

Los problemas morales pueden ser psicológicos de maneras distintas. Hay una Psicología genética del origen de las ideas morales: su surgimiento en tal momento, la aceptación o el rechazo, la expansión plantean preguntas similares de aquellas que presentan las invenciones: un nuevo pensamiento moral es una invención y puede llevar igualmente a aplicaciones. Hay sobre todo una Psicología de la transformación de la vida interior por las ideas morales: lo que en algún momento es una idea abstracta, una norma más o menos impuesta, una convención, puede en otro momento volverse algo natural, una necesidad, una condición de vida. ¿Qué es del trabajo? Se ha dicho en 
algunas ocasiones que se había vuelto una meta y una necesidad, y se ha hablado mucho de la felicidad del trabajo. Pero no se ha dejado de decir también que sigue siendo por algunos lados una actividad penosa. Se ha escrito para finalizar, que desde hace algún tiempo, había signos de una crisis de la "religión del trabajo". Todo esto parece exacto y de ninguna manera contradictorio, y sin duda alguna varios otros factores entran en la motivación en el trabajo y en sus repercusiones en el ser humano.

Esto nos lleva una vez más a considerar al hombre en su totalidad y a abordar el trabajo no solo como técnica, sino también como conducta, y a buscar sus componentes y las capas de significación. Es a la vez una actividad forzada, una acción organizada y continua, un esfuerzo productor, una actividad creadora de objetos y de valores que tiene una utilidad en un grupo, una conducta cuyo motivo puede ser personal ganancia, ambición, gusto, placer, deber, pero cuyo efecto concierne a los otros hombres. Todo esto está dosificado de manera diversa y teñido, según las circunstancias. No hay un trabajo y una moral y una Psicología del trabajo, sino una historia en donde cada momento tuvo su propia complejidad psicológica. Cuando a esta historia se la conozca mejor, tal vez el trabajo nos aparezca como una función psicológica que se forma en un momento dado y se transforma de manera distinta posteriormente.

\section{NOTAS}

1. Hagamos acá nuestro reconocimiento $y$, también, el de la psicología, a nuestros amigos y camaradas de trabajo de esos tiempos quienes respondieron con gracia y prontitud a nuestro llamado, que no podremos olvidar. Constituida en condiciones difíciles y anormales, La Sociedad de Estudios Psicologicos de Toulouse reagrupó numerosos universitarios y científicos de Toulouse (entre ellos el rector de la Universidad y os decanos de las Facultades de Letras y Derecho, el rector del instituto católico) y también a otros científicos de la zona sur.

2. Las páginas que siguen, resumen la exposición que introducía a las dos sesiones de estudio. 